\title{
Use of a meta-analysis to assess the preventive effect of dexmedetomidine on cardiac surgery-associated acute kidney injury
}

\author{
Gui-Zhen Yang, Fu-Shan Xue* (D) and Ya-Yang Liu \\ See related Letter by Shi and Tie, https://ccforum.biomedcentral.com/articles/10.1186/s13054-017-1776-0
}

Shi and Tie [1] concluded in their meta-analysis that dexmedetomidine might be a promising prevention strategy for cardiac surgery-associated acute kidney injury (CSA-AKI). In a meta-analysis, the results from many studies are synthesized mathematically by complex statistical methods to assess the diversity among results and to estimate a common pooled effect with increased precision. Thus, the results of a meta-analysis are only as good as the quality of the collected data. We noted that some defects of the studies included in this metaanalysis would have made interpretation of their conclusions questionable.

First, there is a high heterogeneity among seven included studies, such as studied subjects (pediatric and adult patients), definitions of primary outcomes (creatinine rise, biomarkers, and renal complications), intervention times (unclear, intraoperative, intraoperative and postoperative, and postoperative), doses of dexmedetomidine, and so on.
Second, four of seven included studies were observational studies with significant methodological limitations and a number of confounders, such as a retrospective design or single-center recruitment. There was no attempt in some studies to control most of the risk factors for CSA-AKI, including intraoperative transfusions, hemodynamic instability, use of vasopressors, hemodilution anemia, and so on $[2,3]$.

Third, most of included studies did not assess the effect of dexmedetomidine on the severity and duration of CSA-AKI, although these have highly been associated with postoperative outcomes [4].

Finally, this analysis did not include the recent randomized controlled trial (RCT) by Zhai et al. [5], in which dexmedetomidine decreased the incidence and severity of CSA-AKI in patients undergoing cardiac surgery. The findings of Zhai et al. support the conclusion of this meta-analysis that dexmedetomidine may be beneficial for prevention of CSA-AKI.

\section{Authors' response}

Rui Shi and Hong-Tao Tie

We appreciate the commentary by Yang et al. on our recent publication [1], and we would like to provide a deep discussion according to their concerns.

Inevitably, the studies combined together in a metaanalysis differ. Statistical heterogeneity consists of clinical heterogeneity (variability in participants, interventions, and

\footnotetext{
*Correspondence: xuefushan@aliyun.com; fushan.xue@gmail.com Department of Anesthesiology, Plastic Surgery Hospital, Chinese Academy of Medical Sciences and Peking Union Medical College, 33 Ba-Da-Chu Road, Shi-Jing-Shan District, Beijing, 100144, People's Republic of China
}

outcomes) and methodological heterogeneity (variability in study design) [6].

In our study, we separately pooled cohorts and RCTs to mitigate the influence of methodological heterogeneity. Additionally, although there was no significant heterogeneity in meta-analyses of RCTs or cohorts (RCTs, $P_{\mathrm{H}}=$ $0.52, I^{2}=0 \%$; cohort, $\left.P_{\mathrm{H}}=0.58, I^{2}=0 \%\right)$, a random-effects model was used to reduce the impact of both clinical and methodological heterogeneity.

A retrospective cohort by Turan et al. [7] failed to show a benefit of dexmedetomidine on CSA-AKI, and 
the possible explanation from clinical heterogeneity might be as follows: the different criteria of CSA-AKI, defined as dialysis and anuria, might lead to turbulence of the results. Additionally, a renoprotective effect induced by selective $\alpha 2$-adrenoreceptor inhibition was only present for mild to moderate doses of dexmedetomidine [8], but in the current study the doses and duration of the dexmedetomidine regimen were unclear. Furthermore, CSA-AKI was the secondary outcome in the current cohort. Clinical heterogeneity could also explain the inconsistent effect of dexmedetomidine in RCTs. One RCT [8] reported a null effect of dexmedetomidine on CSA-AKI according to RIFLE classification; preventive effects of dexmedetomidine were observed while renal function was measured by NGAL concentration. NGAL, as an early biomarker of CSA-AKI, was superior to conventional criteria, and the authors finally concluded that dexmedetomidine could be useful in the prevention of CSA-AKI. Based on the aforementioned, the evidence from cohorts and RCTs supports the renoprotection of dexmedetomidine.

Because meta-analysis is based on collected data, it is impossible to assess the effect of dexmedetomidine on the severity and duration of CSA-AKI beyond included studies. The recent RCT by Zhai et al. [5] was not included because it was published online after our manuscript submission. Additionally, the pooled effect after including this RCT also suggested that dexmedetomidine could decrease the CSA-AKI risk (RR 0.42, 95\% CI $0.26-0.69, P=0.0007)$ without significant heterogeneity $\left(P_{\mathrm{H}}=0.75, I^{2}=0 \%\right)$.

In conclusion, we would emphasize that a clue toward but not a definite conclusion of "dexmedetomidine being a promising prevention strategy for CSA-AKI" was drawn, as we summarized in the last sentence of our study.

\section{Abbreviations}

CSA-AKI: Cardiac surgery associated-acute kidney injury; RCT: Randomized controlled trial; RR: Relative risks; Cl: Confidence interval

\section{Acknowledgements}

None.

Funding

None.

Availability of data and materials

Not applicable.

\section{Authors' contributions}

G-ZY, F-SX, and Y-YL carefully read the manuscript by Shi and Tie, and analyzed their methods and data. G-ZY suggested comment points and drafted this manuscript. F-SX and $Y-Y L$ revised the comment points and this manuscript. All authors read and approved the final manuscript.

Ethics approval and consent to participate

Not applicable.
Consent for publication

Not applicable.

\section{Competing interests}

The authors declare that they have no competing interests.

\section{Publisher's Note}

Springer Nature remains neutral with regard to jurisdictional claims in published maps and institutional affiliations.

Received: 16 August 2017 Accepted: 28 September 2017 Published online: 27 March 2018

\section{References}

1. Shi R, Tie HT. Dexmedetomidine as a promising prevention strategy for cardiac surgery-associated acute kidney injury: a meta-analysis. Crit Care. 2017;21(1):198.

2. Fuhrman DY, Kellum JA. Epidemiology and pathophysiology of cardiac surgery-associated acute kidney injury. Curr Opin Anaesthesiol. 2017;30(1):60-5

3. Ortega-Loubon C, Fernández-Molina M, Carrascal-Hinojal Y, Fulquet-Carreras E. Cardiac surgery-associated acute kidney injury. Ann Card Anaesth. 2016; 19(4):687-98.

4. Schiffl H. Severity of post-cardiac surgery acute kidney injury and long-term mortality: is chronic kidney disease the missing link? Crit Care. 2014;18(2):424.

5. Zhai M, Kang F, Han M, Huang X, Li J. The effect of dexmedetomidine on renal function in patients undergoing cardiac valve replacement under cardiopulmonary bypass: a double-blind randomized controlled trial. J Clin Anesth. 2017;40:33-8.

6. Higgins JP, Green S. Cochrane handbook for systematic reviews of interventions. Wiley Online Library. 2008.

7. Turan A, Bashour CA, You J, Kirkova Y, Kurz A, Sessler DI, et al. Dexmedetomidine sedation after cardiac surgery decreases atrial arrhythmias. J Clin Anesth. 2014;26(8):634-42.

8. Balkanay $\mathrm{OO}$, Goksedef D, Omeroglu SN, Ipek G. The dose-related effects of dexmedetomidine on renal functions and serum neutrophil gelatinaseassociated lipocalin values after coronary artery bypass grafting: a randomized, triple-blind, placebo-controlled study. Interact Cardiovasc Thorac Surg. 2015;20(2):209-14.
Submit your next manuscript to BioMed Central and we will help you at every step:

- We accept pre-submission inquiries

- Our selector tool helps you to find the most relevant journal

- We provide round the clock customer support

- Convenient online submission

- Thorough peer review

- Inclusion in PubMed and all major indexing services

- Maximum visibility for your research

Submit your manuscript at www.biomedcentral.com/submit 